\title{
Effects of Storage Time on Molecular Weights and Properties of Melamine-Urea-Formaldehyde Resins ${ }^{1}$
}

\author{
Bora $\mathrm{JEONG}^{2} \cdot$ Byung-Dae PARK (D) $^{2, \dagger} \cdot$ Valerio CAUSIN ${ }^{3}$
}

\begin{abstract}
As the properties of the melamine-urea-formaldehyde (MUF) resins were changing during their storage time, this study investigated the impacts of the synthesis method and melamine content of the MUF resins on the $\mathrm{pH}$, apparent viscosity, molecular weights, and crystallinity to estimate these properties over storage times of up to 30 days. Melaminesat three addition levels $(5,10$, and $20 \mathrm{wt} \%$ based on the resin solids) were simultaneously reacted with urea and formaldehyde (MUF-A resins), while those at the same addition levels were first reacted with formaldehyde and then with urea(MUF-B resins). The $\mathrm{pH}$ values of the MUF-A and MUF-B resins decreased linearly as the storage time increased; the apparent viscosity increased linearly for the low melamine contents (5\% and 10\%) but increased exponentially for $20 \%$. As anticipated, the molecular weights $(M w$ and $M n)$ increased linearly with the storage time, with a steeper increase in the $M w$ of the MUF-B resins compared with that of the MUF-A resins. The crystallinity of the two resin types decreased with storage time at higher melamine content. The relationships between these properties and the storage time made it possible to estimate the property changes in these resins synthesized by the different synthesis methods and melamine contents; this could help predict the properties of such resins in the industry during their storage.
\end{abstract}

Keywords: MUF resins, synthesis method, melamine content, storage time, estimation

\section{INTRODUCTION}

Amino resins such as urea-formaldehyde (UF), melamineformaldehyde (MF), and melamine-urea-formaldehyde (MUF) are the most important thermosetting adhesives in wood-based composite panel manufacturing. Compared to other wood adhesives, UF resins have advantages such as fast curing, excellent performance in the panel, water solubility, and low cost. The disadvantage of using UF adhesives is that they are less resistant to the impact of higher moisture and water. MUF resins can replace both expensive MF resins and high-water resistance resins (No and Kim, 2004; Hse et al., 2008; Hse, 2009). The properties and performance of MUF resins are closely related to the resin's synthesis method and the melamine level. Previous studies have shown that synthesis parameters such as $\mathrm{F} /(\mathrm{U}+\mathrm{M})$ molar ratio, melamine content, and the sequence of melamine addition (in the case of MUF) significantly affect the properties of UF and MUF resins (Dunky, 1998; Pizzi and Mittal,

\footnotetext{
${ }^{1}$ Date Received September 23, 2019, Date Accepted April 16, 2020

${ }^{2}$ Department of Wood and Paper Science, Kyungpook National University, Daegu 41566, Republic of Korea

${ }^{3}$ Departimento di Scienze Chimiche, Università di Padova, via Marzolo 135131 Padova, Italy

$\dagger$ Corresponding author: Byung-Dae PARK (e-mail: byungdae@knu.ac.kr, ORCID: 0000-0002-9802-7855)
} 
2003; No and Kim, 2004; Hse et al., 2008, GavrilovićGrmuša et al., 2010a, 2010b; Paiva et al., 2012, Hong et al., 2017a,b). These results reported that thickness of the interphase region and the depth of penetration into the wood were related to the resin viscosity. Longterm storage stability is an important factor in the industrial use of MUF resins as wood adhesives. Previous studies have shown that the amount of hydroxymethylated melamine species decrease during storage and that the condensation reaction between hydroxymethylgroups progresses to a certain extent during storage (Malkin and Kulichikhin, 1991; Johromi, 1999; Mijatovic et al., 2002; No and Kim, 2004).

Given the importance, many publications have reported measurements of molecular weight (MW) of MUF resins using gel permeation chromatography (GPC) or size exclusion chromatography (SEC) (Zanetti and Pizzi, 2003; Despres and Pizzi, 2006; Lei et al., 2006; Pendlebury et al., 2010; Paiva et al., 2013; Jeong and Park, 2016, 2019, Jeong et al., 2019, Lubis et al., 2019a, b). For example, MWs and the chain length of MF resins also impacted the storage stability of MF resins (Jahromi, 1999a, 1999b). When the chains are too short, a greater amount of hydrogen bonds may be formed between the chains and the resin will solidify and precipitate. Meanwhile, when the chains are too long, the viscosity becomes too high, which makes the application difficult and reduces the penetration of the adhesive into the wood-based substrate (Johnson and Kamke, 1992; Jeremejeff, 2012; Nuryawan et al., 2014; Jeong and Park, 2016; Jeong and Park, 2019, Hong et al., 2017a, b). Thus, adequate chain length and branches of sufficient branching will prevent the formation of hydrogen bonds and improve the resin's storage stability (Jahromi, 1999a, 1999b). Although lots of research has focused on the storage stability of MF and MUF resins, there has been very limited work on the estimation of property changes in these resins over storage time. Therefore, we attempted to estimate the changes in properties such as $\mathrm{pH}$, apparent viscosity, MWs, and crystallinity in MUF resins prepared by two different synthesis methods and for three melamine contents as a function of storage time for up to 30 days.

\section{MATERIALS and METHODS}

\subsection{Materials}

Melamine (99\%), urea granules (99\%), and formalin (37\%) used in the synthesis of MUF resin adhesives in this work are of technical grade from Daejung Chemical, Korea. Aqueous solutions of formic acid (20 $\mathrm{wt} \%$ ) and sodium hydroxide (20 wt $\%$ ) were added to adjust the $\mathrm{pH}$ during the resin synthesis process. An aqueous solution of ammonium chloride (20 wt\%) was used as a hardener. High-purity ( $\geq 99.9 \%) \mathrm{N}, \mathrm{N}$-dimethyl formamide (DMF) and dimethylsulfoxide (DMSO) of high-performance liquid chromatography (HPLC) grade were purchased from Sigma-Aldrich in Korea and used without further treatment.

\subsection{Methods}

\subsubsection{Synthesis of MUF resins}

Two types of resins, namely MUF-A and MUF-B, were synthesized in this study. First, MUF-A resins were synthesized using an alkaline-acid-alkaline threestep reaction (Jeong et al., 2019). Around $580 \mathrm{~g}$ of formalin was placed in a reactor equipped with a mantle heater. The $\mathrm{pH}$ was adjusted to $8.2-8.5$ by adding sodium hydroxide (20 wt $\%$ ). First, urea and melamine (at three levels of 5,10, and 20\%) were simultaneously added into the reactor at the $\mathrm{F} /(\mathrm{M}+\mathrm{U})$ molar ratio of 1.5 under continuous stirring at $40^{\circ} \mathrm{C}$. The temperature was increased to $90^{\circ} \mathrm{C}$ and maintained for $1 \mathrm{~h}$. Then, the $\mathrm{pH}$ was adjusted to $6.5-7.0$ with formic acid (20 wt $\%$ ) for the condensation reaction. When the target resin viscosity of the "B" and " $\mathrm{C}$ " scale of a bubble viscometer (VG-9100, BYK Gardner, Columbia, Maryland, USA) 
Effects of Storage Time on Molecular Weights and Properties of Melamine-Urea-Formaldehyde Resins

reached at $90^{\circ} \mathrm{C}$. After the target viscosity was reached, the $\mathrm{pH}$ was adjusted to $7.5-8.0$ with $20 \% \mathrm{NaOH}$. Then, the second urea was added into the reactor to obtain MUF-A resins with the final $\mathrm{F} /(\mathrm{M}+\mathrm{U})$ molar ratio of 1.0 , which subsequently decreased the temperature to $60^{\circ} \mathrm{C}$ and reacted for $20 \mathrm{~min}$. The MUF-A resins were cooled to ambient temperature and the $\mathrm{pH}$ was adjusted to $9.0-9.2$ prior to further analysis.

Secondly, MUF-B resins were synthesized using an alkaline-alkaline-acid three-step reaction. Formalin was added to the reactor and the $\mathrm{pH}$ was adjusted to $8.2-8.5$ by adding sodium hydroxide as in the MUF-A resin synthesis. The relevant amounts of melamine to achieve the final content of melamine of 5, 10, and $20 \%$, respectively, were added to the reactor under continuous stirring at $40^{\circ} \mathrm{C}$. Then, the temperature was increased to $90^{\circ} \mathrm{C}$ and was maintained for $1 \mathrm{~h}$. Then, the first urea was added to the reactor to adjust the same $\mathrm{F} /(\mathrm{M}+\mathrm{U})$ molar ratio of 1.5 for all three versions of different final melamine contents and maintained for 10 minutes. Then, the $\mathrm{pH}$ was adjusted to 6.5-7.0 with formic acid (20 wt $\%$ ) for the condensation reaction until the target resin viscosity was between the " $\mathrm{B}$ " and " $\mathrm{C}$ " scale of the bubble viscometer. After the target viscosity was reached, the $\mathrm{pH}$ was adjusted to $7.5-8.0$ with $20 \%$ $\mathrm{NaOH}$. Then, the second urea portion was added to the reactor to obtain the final $\mathrm{F} /(\mathrm{M}+\mathrm{U})$ molar ratio of 1.0 , which consequently decreased the temperature to $60^{\circ} \mathrm{C}$, which was maintained for $20 \mathrm{~min}$. Finally, MUF-B resins were cooled to ambient temperature and the $\mathrm{pH}$ was adjusted to $9.0^{-9.2}$ prior to further analysis.

\subsubsection{Properties of MUF resins}

The water-tolerance value was determined by adding a certain amount of water to a $1 \mathrm{~g}$ resin sample in the tube by checking the clouding point of the resin samples at $20^{\circ} \mathrm{C}$. The viscosity of all resins was measured with a cone-plate viscometer (DV-II+, Brookfield, Middleboro, MA, USA), using spindle No. 2 at $25^{\circ} \mathrm{C}$ and $60 \mathrm{rpm}$.
The non-volatile solids content of each sample was calculated by measuring the resin mass before and after drying in the oven at $105^{\circ} \mathrm{C}$ for $3 \mathrm{~h}$. The gelation time of all the resins was measured at $100{ }^{\circ} \mathrm{C}$ by adding 3 $\mathrm{wt} \% \mathrm{NH}_{4} \mathrm{CI}$ (added in the form of a $20 \mathrm{wt} \%$ solution) based on the resins solids content using a gel time meter (DAVIS, Sunshine Instruments, USA).

\subsubsection{MW measurements of MUF resins}

A GPC (YL9100, Younglin, Korea) system equipped with a refractive index (RI) detector was used to measure the MW of the resins. The columns used were KD 801, 802, and $806 \mathrm{M}$ (SHODEX, Japan). The GPC was performed at $50^{\circ} \mathrm{C}$ for the column and detector temperatures and a flow rate of $0.5 \mathrm{ml} / \mathrm{min}$ (Jeong and Park, 2017). The universal calibration of MW between 106 and 25,200 Da was performed using polyethylene glycol (PEG) standards from Polymer Standards Service GmbH, Germany. A HPLC-grade DMF was used as the mobile phase. The resin samples were dissolved in a mixture of $10 \% \mathrm{DMSO}$ and $90 \% \mathrm{DMF}$ and kept in an oven at $50^{\circ} \mathrm{C}$ for $3 \mathrm{~h}$ before injection. The sample solution was then introduced via the injection loop of the GPC through a $0.45 \mathrm{~mm}$ filter. The weight-average molecular weight $(M w)$, number-average molecular weight $(\mathrm{Mn})$, polydispersity (PDI), and low molecular weight (LMW) and high molecular weight (HMW) fractions were calculated using YL-Clarity chromatography software (Younglin, Gyeonggi-do, Korea).

\subsubsection{Crystallinity of MUF resins}

X-ray diffraction (XRD) (D/Max-2500 Rigaku, Tokyo, Japan) was used to investigate the crystallinity of the two types of MUF resins with the three melamine contents after different storage times. The MUF resins were thoroughly cured at $120^{\circ} \mathrm{C}$ for one day after $3 \mathrm{wt} \%$ $\mathrm{NH}_{4} \mathrm{CI}$ (added in form of a $20 \mathrm{wt} \%$ solution). Cured MUF resins then were ground to obtain the powder resins with 180-250 $\mu \mathrm{m}$ size. The powder samples were 
Table 1. Properties of two types of MUF resins synthesized with three melamine contents

\begin{tabular}{ccccccc}
\hline Resin type & $\begin{array}{c}\text { Melamine content } \\
(\%)\end{array}$ & $\mathrm{pH}$ & $\begin{array}{c}\text { Viscosity } \\
(\mathrm{mPa} \cdot \mathrm{s})\end{array}$ & $\begin{array}{c}\text { Non-volatile solids content } \\
(\mathrm{wt} \%)\end{array}$ & $\begin{array}{c}\text { Gelation time } \\
(\mathrm{s})\end{array}$ & $\begin{array}{c}\text { Water-tolerance } \\
(\%)\end{array}$ \\
\hline \hline \multirow{3}{*}{ MUF-A } & 5 & 9.4 & 58 & $61.6 \pm 0.1$ & $204 \pm 2$ & 100 \\
& 10 & 9.1 & 65 & $61.7 \pm 0.1$ & $174 \pm 3$ & 80 \\
& 20 & 9.3 & 84 & $61.9 \pm 0.2$ & $134 \pm 2$ & 30 \\
\hline \multirow{3}{*}{ MUF-B } & 5 & 8.8 & 57 & $59.3 \pm 0.2$ & $197 \pm 3$ & 160 \\
& 10 & 8.9 & 64 & $61.2 \pm 0.1$ & $168 \pm 3$ & 100 \\
& 20 & 8.9 & 84 & $62.4 \pm 0.1$ & $106 \pm 2$ & 30 \\
\hline
\end{tabular}

analyzed at ambient temperature using a $\mathrm{CuK}_{\alpha 1} \mathrm{X}$-ray source with a wavelength ( $\lambda$ ) of $1.540 \AA$ in the angular range $10-60^{\circ}$ of $2 \theta$ with a step of $0.02 \%$ min. The percent crystallinity of MUF-A and MUF-B resins with three melamine contents during aging was determined by deconvoluting the total area of the diffractograms and obtaining the individual contributions of the crystalline and amorphous regions. Thus, the degree of crystallinity by weight was obtained by applying the least-squares fit procedure elaborated by Hindeleh and Johnson (1971).

\section{RESULTS and DISCUSSION}

Table 1 presents the properties of two MUF resins at three melamine contents. MUF-A resins had similar resin solids content, while those of MUF-B resins slightly increased as the melamine content increased.

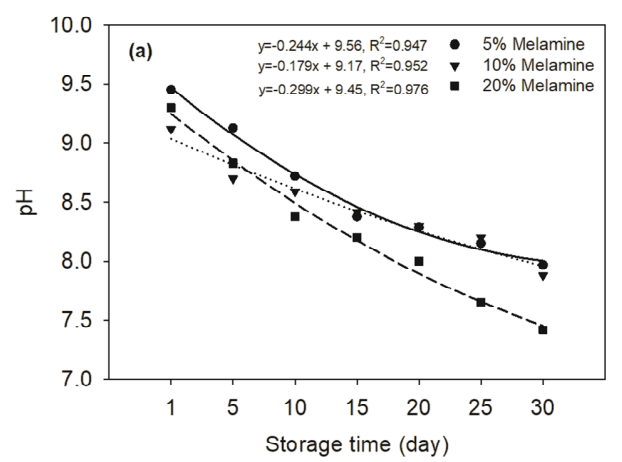

This could be due to the melamine content and amount of the second urea for MUF-B resins. The viscosity of these resins increased gradually as the melamine content increased. Moreover, the gelation time of the MUF-B resins was much shorter than those of the MUF-A resins and it decreased as the melamine content increased. The water tolerance values after their synthesis were close together even though they were lower than the target values, indicating proper control of the synthesis of these resins.

Fig. 1 shows the change of $\mathrm{pH}$ of MUF-A (Fig. 1a) and MUF-B resins (Fig. 1b) at $25^{\circ} \mathrm{C}$ as a function of the storage time. The $\mathrm{pH}$ of the two resins linearly decreased over the storage time for up to30 days. Based on the slope of the equation of MUF-A resins showed a greater decrease in $\mathrm{pH}$ than those of MUF-B resins, indicating the instability in their storage. A decrease in

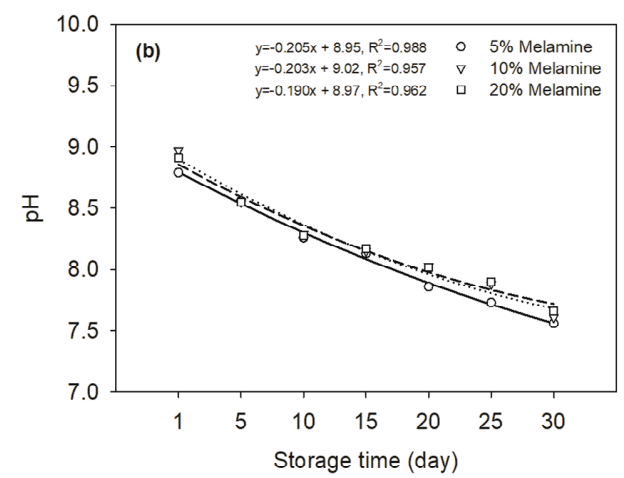

Fig. 1. The $\mathrm{pH}$ changes of two MUF resins with three melamine contents as a function of storage rime at $25^{\circ} \mathrm{C}$. (a) MUF-A resins, and (b) MUF-B resins. 
the $\mathrm{pH}$ could be due to the hydrolysis of hydroxymethylated ureas, which disintegrate into ammonia $\left(\mathrm{NH}_{3}\right)$ and isocyanic acid(HNCO), which quickly decomposes to $\mathrm{NH}_{3}$ and carbon dioxide $\left(\mathrm{CO}_{2}\right)$ (Mattheij et al. 2005). $\mathrm{NH}_{3}$ reacts with formaldehyde to produce slightly basic hexamethylenetetramine. Thus, the effects of $\mathrm{CO}_{2}$ will prevail during resin storage, which will consequently decrease the $\mathrm{pH}$ of either MUF-A or MUF-B resins. In addition, the Cannizzaro reaction is a base-catalyzed disproportionate reaction of an aldehyde, devoid of $\alpha-\mathrm{H}$ atoms, decrease the $\mathrm{pH}$. All linear equations between the $\mathrm{pH}$ and storage time showed high regression coefficients and made it possible to estimate the $\mathrm{pH}$ change over the storage time.

As shown in Fig. 2, the apparent viscosity of two MUF resins linearly increased at 5 and $10 \%$ melamine content. However, it exponentially increased at $20 \%$ melamine content, regardless of the synthesis method. As expected, these results indicate that the resins prepared with the lower melamine contents are relatively stable in storage for up to 30 days. However, the $20 \%$ melamine addition limited the safe storage stability for the two resins to only about 20 days. These results could be responsible for chemical changes during storage. For example, Early (Malkin and Kulichikhin, 1991; Johromi, 1999; Mijatovic et al., 2002; No and Kim,

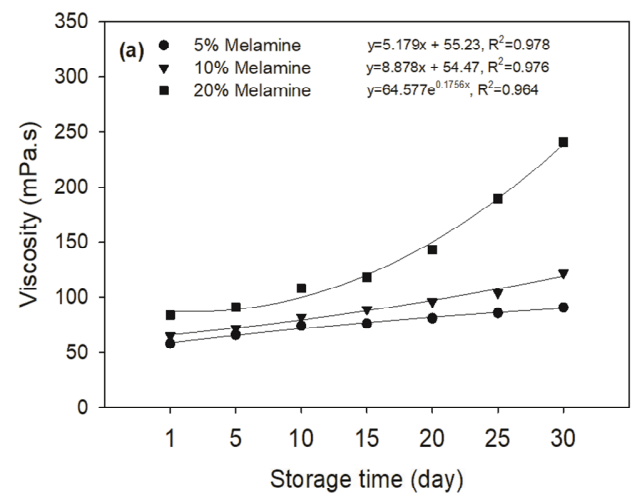

2004) studies showed that the amount of hydroxymethyl melamine and substituted melamine compounds decreased during storage and the condensation reaction between hydroxymethyl groups preceded to a certain extent during storage. In addition, it was reported that the most widespread change during the storage of MUF-A resins was the formation of hydrogen bonds between the chains (Siimer et al., 2005). Hydrogen bonds were formed between fully lone electron pairs of carbonyl oxygen and hydroxymethyl groups and hydrogen of electronegative atoms of free amine groups. Water present in the resin was also likely involved in the formation of hydrogen bonds. The number of hydrogen bonds increased over time and hence the viscosity, making even the application of the adhesive more difficult (Siimer et al., 2005).

To understand the increase in resin viscosity, the molecular weights (MWs) of the two MUF resins were determined by GPC. Fig. 3 presents the typical GPC chromatograms of the two resins with three melamine contents resins immediately after their synthesis. The two types of resin have four major peaks. These two resins with $20 \%$ melamine content showed higher and wider peaks than those with low melamine content, indicating greater MW. The MW of a polymer chain also affects the storage stability. If a chain is too long,

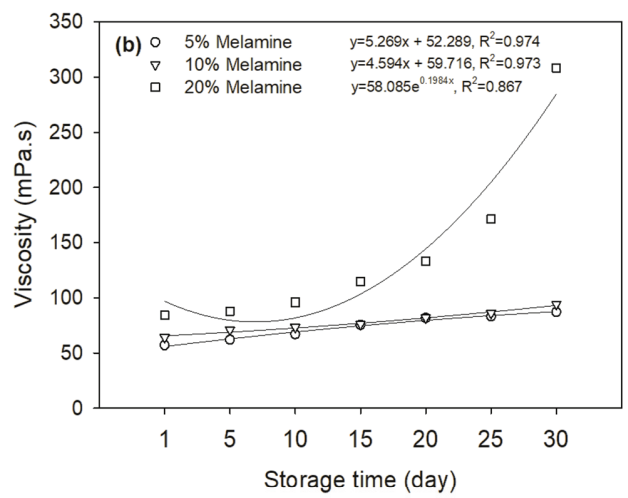

Fig. 2. Changes of the apparent viscosity in the two MUF resins with three melamine contents as a function of storage time. (a) MUF-A resins, and (b) MUF-B resins. 
(a)

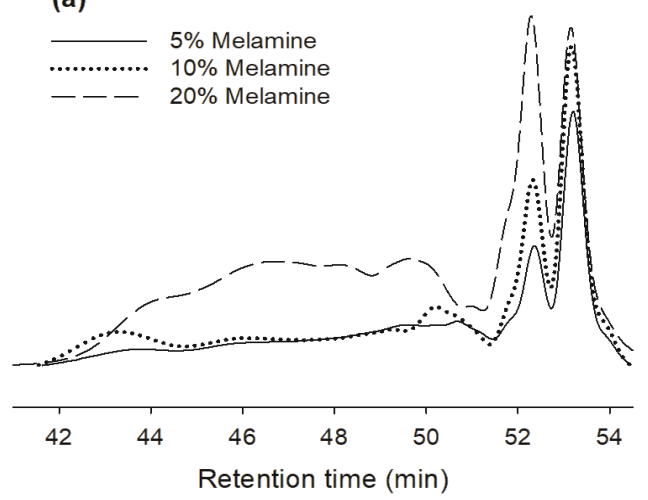

(b)

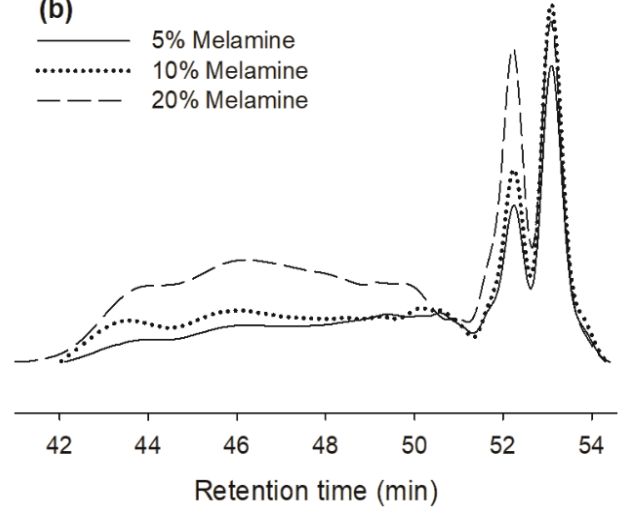

Fig. 3. Typical GPC chromatograms of two MUF resins at three melamine content levels. (a) MUF-A resin at 0 days, and (b) MUF-B resin at 0 days.

more hydrogen bonds may be formed between the chains and the resin will then solidify and precipitate. The long chains with their high MW increase the resin viscosity, making it difficult to apply the resin uniformly and reducing the adhesive penetration into the substrate. Thus, moderate length chains with sufficient amounts of branches will prevent the formation of hydrogen bonds and improve the stability of resin storage (Jahromi, 1999a).

Fig. 4 and Table 2 compare the fraction of low MW (LMW) within closer the retention time near 54 minutes and high MW (HMW) within closer the retention time near 46 minutes in the two types of resins prepared with the three melamine content levels at different storage times. As the melamine contents increased in the two MUF resin types, the HMW fraction increased and the LMW fraction decreased. In addition, the HMW fraction of the two MUF resin types clearly increased as the storage time increased. After 30 days, the LMW fraction decreased and the HMW fraction increased. As the storage time reached 30 days, the LMW fraction of the MUF-A resins became greater than those of the MUF-B resins. However, the HMW fraction of the MUF-B resin was much greater than its counterpart in the MUF-A resins, which may be due to differences in how melamine reacts with formaldehyde before urea (Kim et al., 2006). In other words, melamine, formaldehyde, and urea react simultaneously for MUF-A resins, which produce a greater amount of the LMW fraction. When the melamine reacts with formaldehyde first and then with urea, the MUF-B resins result in a lesser amount of the LMW fraction.

Fig. 5 presents both $M n$ and $M w$ of two MUF versions with three melamine contents. As the melamine content increased, both the $M n$ and $M w$ of two MUF resins increased (Fig. 5a and b), which was compatible with an increase in the resin viscosity. However, the $M n$ and $M w$ of MUF-B resins were higher than those of the MUF-A resins, indicating that more polymeric materials were formed. In addition, the MUF-B resins had higher MW than the MUF-A resins; this is because the addition reaction of formaldehyde to melamine is much easier and more complete than those of urea (Kim et al., 2006).

Linear relationships between $\mathrm{MW}$ and storage time were established for two MUF resins with three melamine contents, making it possible to estimate the change of $M n$ and $M w$ over the storage time. In particular, MUF-A and MUF-B resins showed a significantly rapid increase in the $M n$ and $M w$ for the 

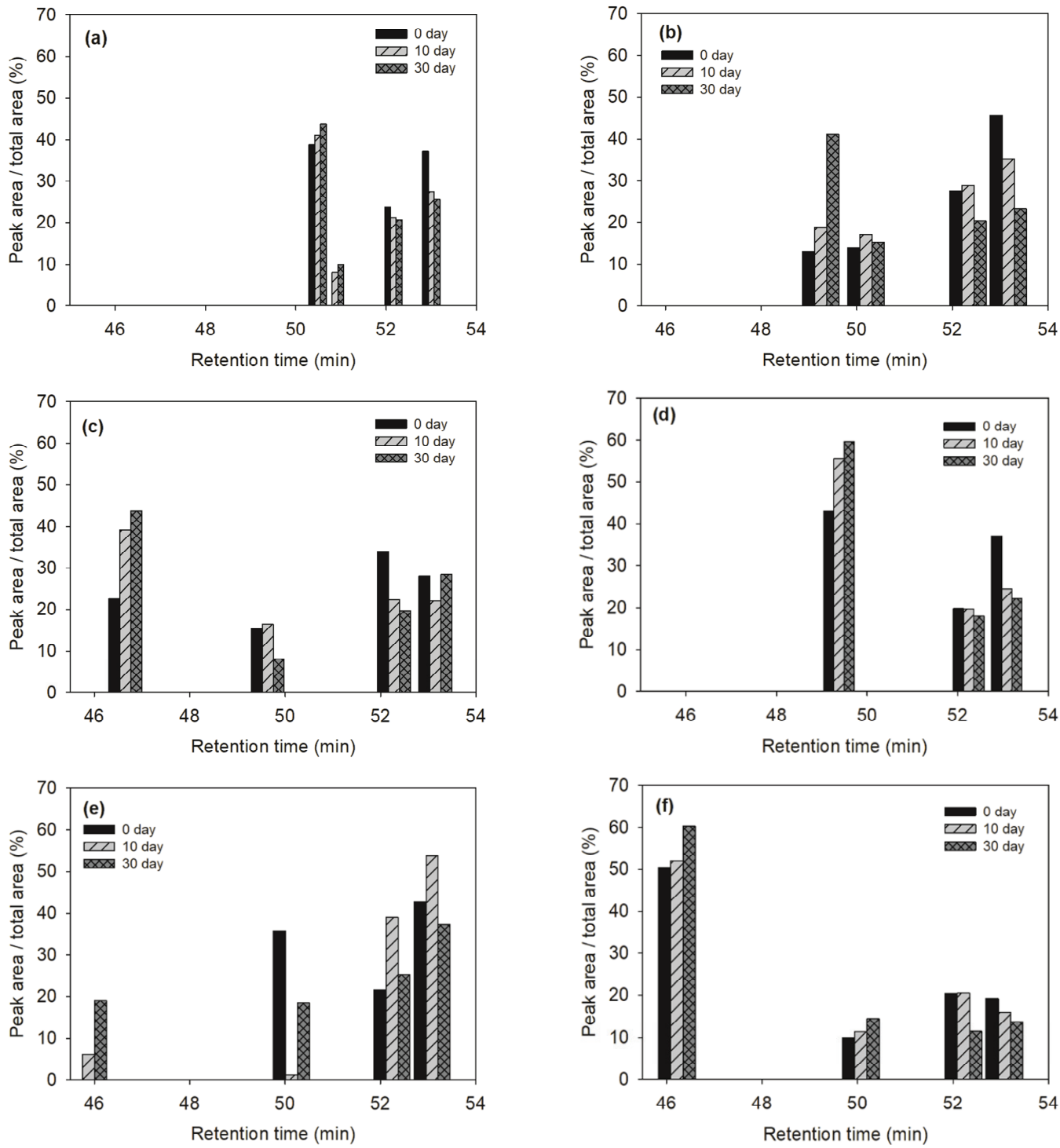

Fig. 4. Peak area per total area for the resins prepared with three melamine contents. MUF-A resins with $5 \%$ (a), $10 \%$ (b), and 20\%melamine content(c), respectively. MUF-B resins with $5 \%$ (d), $10 \%$ (e), and $20 \%$ (f) melamine content, respectively.

$20 \%$ melamine level, especially for MUF-B type. In addition, the polydispersity index $(\mathrm{PDI}=M w / M n)$ values of these resins increased as the melamine content increased (Table 3 and 4), which was consistent with the changes of $M n$ and $M w$. However, the PDI values of these resins showed an inconsistency over the storage time (Table 4). The PDI values of the two MUF resins slightly increased at the $10 \%$ melamine content level as the difference between $M n$ and $M w$ widened over 10 days of storage. Then, the PDI decreased except 
Table 2. Peak area per the total area of two types of MUF resins at three melamine contents

\begin{tabular}{|c|c|c|c|c|c|}
\hline \multirow{2}{*}{ Melamine content $(\mathrm{wt} \%)$} & \multirow{2}{*}{ Resin type } & \multirow{2}{*}{ Peak number } & \multicolumn{3}{|c|}{ Peak area $(\%)$} \\
\hline & & & 0 day & 10 day & 30 day \\
\hline \multirow{9}{*}{5} & \multirow{5}{*}{ MUF-A } & Peak 1 & 38.8 & 41.1 & 433.7 \\
\hline & & Peak 2 & & 8.2 & 10.0 \\
\hline & & Peak 3 & 23.8 & 21.1 & 20.7 \\
\hline & & Peak 4 & 37.4 & 29.6 & 25.6 \\
\hline & & Total area $(\%)$ & 100 & 100 & 100 \\
\hline & \multirow{4}{*}{ MUF-B } & Peak 1 & 43.1 & 55.6 & 59.6 \\
\hline & & Peak 2 & 19.8 & 19.7 & 18.2 \\
\hline & & Peak 3 & 37.1 & 24.7 & 22.2 \\
\hline & & Total area $(\%)$ & 100 & 100 & 100 \\
\hline \multirow{10}{*}{10} & \multirow{5}{*}{ MUF-A } & Peak 1 & 13.0 & 18.8 & 41.1 \\
\hline & & Peak 2 & 13.9 & 17.1 & 15.3 \\
\hline & & Peak 3 & 27.4 & 28.9 & 20.3 \\
\hline & & Peak 4 & 45.7 & 35.2 & 23.2 \\
\hline & & Total area $(\%)$ & 100 & 100 & 100 \\
\hline & \multirow{5}{*}{ MUF-B } & Peak 1 & & 6.1 & 19.0 \\
\hline & & Peak 2 & 35.7 & 1.2 & 18.5 \\
\hline & & Peak 3 & 21.6 & 39.0 & 225.2 \\
\hline & & Peak 4 & 42.7 & 53.8 & 37.2 \\
\hline & & Total area $(\%)$ & 100 & 100 & 100 \\
\hline \multirow{10}{*}{20} & \multirow{5}{*}{ MUF-A } & Peak 1 & 22.4 & 39.1 & 43.7 \\
\hline & & Peak 2 & 15.4 & 16.4 & 8.1 \\
\hline & & Peak 3 & 33.9 & 22.3 & 19.7 \\
\hline & & Peak 4 & 28.0 & 22.2 & 28.4 \\
\hline & & Total area $(\%)$ & 100 & 100 & 100 \\
\hline & \multirow{5}{*}{ MUF-B } & Peak 1 & 50.4 & 52.0 & 60.2 \\
\hline & & Peak 2 & 10.0 & 11.4 & 14.6 \\
\hline & & Peak 3 & 20.4 & 20.5 & 11.5 \\
\hline & & Peak 4 & 19.2 & 16.1 & 13.8 \\
\hline & & Total area $(\%)$ & 100 & 100 & 100 \\
\hline
\end{tabular}
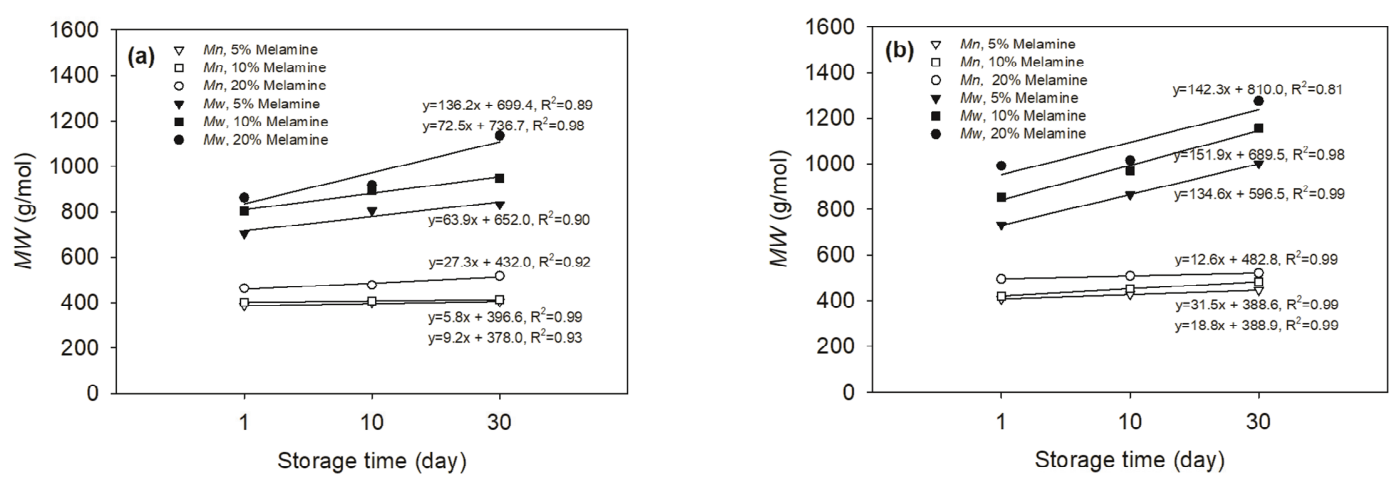

Fig. 5. $M n$ and $M w$ of two MUF resins with three melamine contents as a function of storage time. (a) MUF-A resins, and (b) MUF-B resins. 
Effects of Storage Time on Molecular Weights and Properties of Melamine-Urea-Formaldehyde Resins

Table 3. $M n$ and $M w$ of two MUF resins with three melamine contents as the function of storage time

\begin{tabular}{cccccccc}
\hline \multirow{2}{*}{ Resin type } & $\begin{array}{c}\text { Melamine content } \\
(\text { wt \%) }\end{array}$ & \multicolumn{2}{c}{0 day } & \multicolumn{2}{c}{ 10days } & \multicolumn{2}{c}{30 days } \\
\cline { 2 - 8 } & 5 & $390 \pm 2$ & $715 \pm 12$ & $402 \pm 3$ & $803 \pm 13$ & $464 \pm 3$ & $863 \pm 9$ \\
\hline \hline \multirow{3}{*}{ MUF-A } & 10 & $399 \pm 4$ & $804 \pm 10$ & $408 \pm 4$ & $894 \pm 8$ & $477 \pm 5$ & $918 \pm 13$ \\
& 20 & $404 \pm 3$ & $832 \pm 9$ & $414 \pm 6$ & $948 \pm 9$ & $518 \pm 2$ & $1135 \pm 12$ \\
\hline \multirow{3}{*}{ MUF-B } & 5 & $407 \pm 3$ & $731 \pm 3$ & $420 \pm 3$ & $853 \pm 14$ & $495 \pm 6$ & $992 \pm 14$ \\
& 10 & $427 \pm 4$ & $864 \pm 12$ & $452 \pm 7$ & $970 \pm 12$ & $509 \pm 4$ & $1016 \pm 16$ \\
& 20 & $445 \pm 7$ & $1000 \pm 15$ & $483 \pm 6$ & $1158 \pm 19$ & $520 \pm 7$ & $1276 \pm 9$ \\
\hline
\end{tabular}

Table 4. PDI of two MUF resins with three melamine content levels over the storage time

\begin{tabular}{ccccc}
\hline \multirow{2}{*}{$\begin{array}{c}\text { Resin } \\
\text { type }\end{array}$} & $\begin{array}{c}\text { Melamine } \\
\text { content } \\
\text { (wt \%) }\end{array}$ & \multicolumn{3}{c}{ PDI } \\
\cline { 3 - 5 } & 5 & 1.83 & 2.00 & 1.86 \\
\hline \hline \multirow{2}{*}{ MUF-A } & 10 & 2.01 & 2.19 & 1.92 \\
& 20 & 2.06 & 2.29 & 2.19 \\
\hline \multirow{3}{*}{ MUF-B } & 5 & 1.80 & 2.03 & 2.00 \\
& 10 & 2.02 & 2.15 & 2.00 \\
& 20 & 2.25 & 2.40 & 2.45 \\
\hline
\end{tabular}

the MUF-B resins with $20 \%$ melamine content.

Fig. 6 shows the typical XRD patterns of two MUF resins with three melamine contents at 30 days. As shown, the sharpness and intensity of the crystalline region decreases markedly as the melamine content increases, indicating a decrease in the resin's crystallinity. In other words, the two types of resins showed crystallinity with up to $10 \%$ melamine content, indicating that these resins contain crystals or crystalline domains in the cured state. The resins at 20\% melamine content were amorphous after more than 10 days of storage although at the start of the storage the crystallinity of the $20 \%$ MUF-A resin was higher compared to the $20 \%$ MUF-B resin. The crystallinity of the MUF-A resins slightly decreased up to 10 days of storage and then leveled off as the storage time increased from 10 days to 30 days, whereas the MUF-B resins with the two lower melamine contents showed different behavior, but all in all no big changes (Fig. 7).
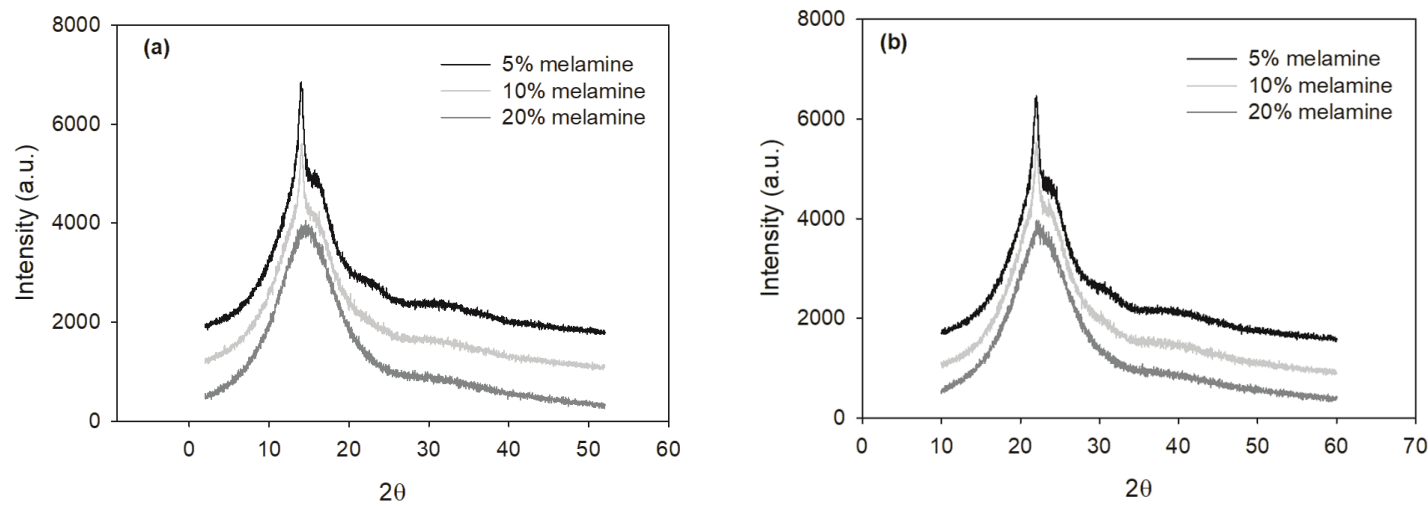

Fig. 6. Typical XRD patterns of the resins with three melamine contents. (a) MUF-A resins at 30 days, and (b) MUF-B resins at 30 days. 

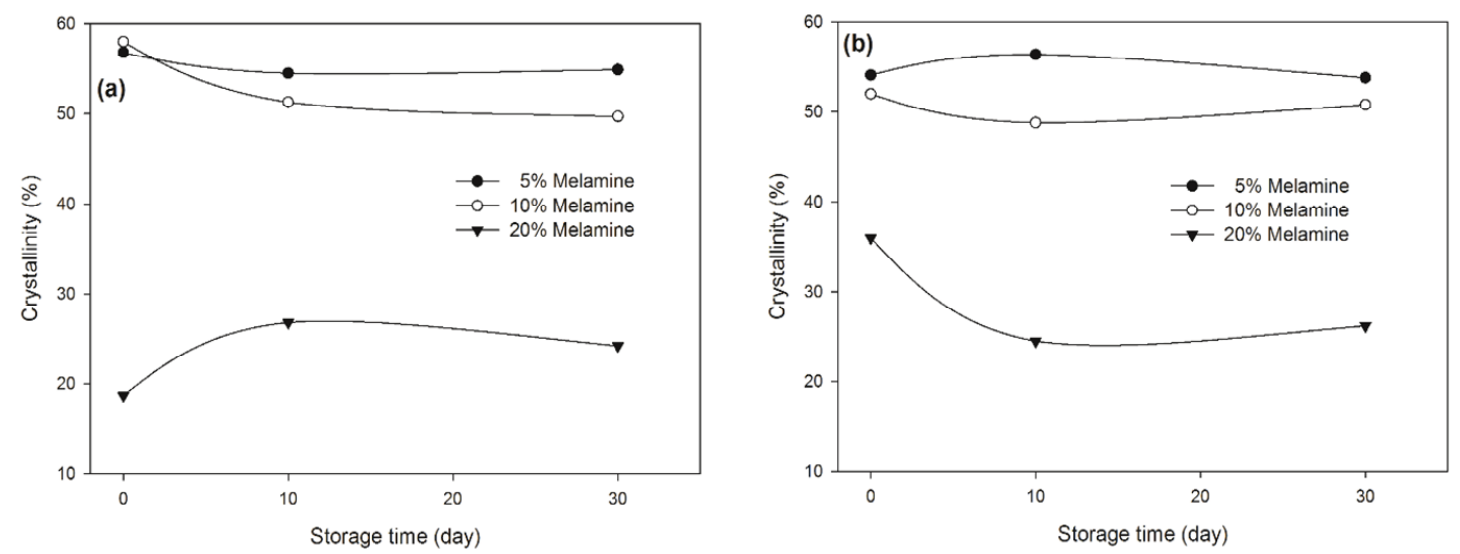

Fig. 7. Change in the crystallinity of the two MUF resin versions with three melamine contents. (a) MUF-A resins, and (b) MUF-B resins.

\section{CONCLUSIONS}

This study attempted to estimate changes of the properties of two types of MUF resins prepared with different synthesis methods and melamine contents over their storage time of up to 30 days. We investigated the $\mathrm{pH}$, apparent viscosity, molecular weights, and crystallinity for estimation in industrial practice. The $\mathrm{pH}$ values of the MUF-A and MUF-B resins decreased linearly over the storage time while the apparent viscosity increased linearly at low melamine contents (5 and 10\%) but exponentially at $20 \%$ melamine content. As expected, the molecular weights ( $M w$ and $M n)$ linearly increased over the storage time, with steeper increase for $M w$, especially for the MUF-B version with $20 \%$ melamine. The two resins with 5 and $10 \%$ melamine level show crystallinity in the cured resin, whereas the two $20 \%$ versions remained amorphous. These relationships between the resin properties and storage time help to predict resin properties over storage time.

\section{ACKNOWLEDGMENTS}

This study was carried out with the support of R\&D
Program for Forest Science Technology (Project No.: 2019149C10-2023-0301) provided by Korea Forest Service (Korea Forestry Promotion Institute).

\section{REFERENCES}

Despres, A., Pizzi, A. 2006. Colloidal aggregation of aminoplastic polycondensation resins: urea-formaldehyde versus melamine-formaldehyde and melamine-urea-formaldehyde Resins, Journal of Applied Polymer Science 100: 1406-1412.

Dunky M. 1998 Urea-formaldehyde (UF) adhesive resins for wood. International Journal of Adhesives and Adhesion 18(2): 95-107.

Gavrilović-Grmuš, I., Dunky, M., Miljković, J., DjiporovićMomčilović, M. 2010a. Radial penetration of ureaformaldehyde adhesive resins into beech (Fagus Moesiaca) Journal of Adhesion Science and Technology 24(8-10): 1753-1768.

Gavrilović-Grmuša, I., Miljković, J., ĐiporovićMomčilović, M. 2010b. Influence of the degree of condensation on the radial penetration of ureaformaldehyde adhesives into silver fir (Abies alba, Mill.) wood tissue. Journal of Adhesion Science and 
Effects of Storage Time on Molecular Weights and Properties of Melamine-Urea-Formaldehyde Resins

Technology 24(8-10): 1437-1453.

Hong, M.K., Park, B.D. 2017a. Effect of ureaformaldehyde resin adhesive viscosity on plywood adhesion. Journal of the Korean Wood Science and Technology 45(2): 223-231.

Hong M,K., Park, B.D., Kim, K.H., Shim, K. 2017 b. Performance of Melamine-Urea-Formaldehyde Resin Adhesives at Various Melamine Contents for Bonding Glued Laminated Timber Under High Frequency Heating. Journal of the Korean Wood Science and Technology 45(4): 409-418.

Hse, C.Y., Fu, F., Pan, H. 2008. Melamine-modified urea formaldehyde resin for bonding particleboards. Forest Products Journal 58(4): 56-61.

Hse, C.Y. 2009. Development of melamine modified urea formaldehyde resins based on strong acidic $\mathrm{pH}$ catalyzed urea formaldehyde polymer. Forest Products Journal 59(4): 19-25.

Hindeleh, A.M., Johnson, D.J. 1971. The resolution of multipeak data in fibre science. Journal of Physics D: Applied Physics 4: 259-263.

Jahromi, S. 1999a. Storage stability of melamineformaldehyde resin solutions, 1 . The mechanism of instability. Macromolecular Chemistry and Physics 200(10): 2230-2239.

Jahromi, S. 1999b. The storage stability of melamine formaldehyde resin solutions: III. Storage at elevated temperatures. Polymer 40(18): 5103-5109.

Jeong, B., Park, B.D. 2019. Effect of molecular weight of urea-formaldehyde resins on their cure kinetics, interphase, penetration into wood, and adhesion in bonding wood .Wood Science and Technology 53(3): 665-685.

Jeong, B., Park, B.D. 2016. Measurement of molecular weights of melamine-urea-formaldehyde resins and their influences to properties of medium density fiberboards. Journal of the Korean Wood Science and Technology 44(6): 913-922.

Jeong, B., Park, B.D. 2017. Effect of analytical parameters of gel permeation chromatography on molecular weight measurements of urea-formaldehyde resins. Journal of the Korean Wood Science and Technology 45(4): 471-481.

Jeong, B., Park, B.D., Causin, V. 2019. Influence of synthesis method and melamine content of ureamelamine-formaldehyde resins to their features in cohesion, interphase, and adhesion performance. Journal of Industrial Engineering and Chemistry 79: 87-96.

Jeremejeff, J.2012. Investigation of UF-resins- The Effect of The Formaldehyde/Urea Mole Ratio During Synthesis, Master of Science Thesis, KTH Royal Institute of Technology, Stockholm, Sweden, Johnson, S.E., Kamke, F.A. 1992. Quantitative analysis of gross adhesive penetration in wood using fluorescence microscopy. Journal of Adhesion 40: 47-61.

Kim, S., Kim, H.J., Kim, H.S., Lee, Y.K., Yang, H.S. 2006. Thermal analysis study of viscoelastic properties and activation energy of melaminemodified urea formaldehyde resins. Journal of Adhesion Science and Technology 20(8): 803-816.

Lei, H., Pizzi, A., Du, G., Despres, A. 2006. Variation of MUF and PMUF resins mass fractions during preparation. Journal of Applied Polymer Science 100(6): 4842-4855.

Lubis, M.A.R., Park, B.D., Lee, S.M. 2019a. Performance of Hybrid Adhesives of Blocked- pMDI/MelamineUrea-Formaldehyde Resins for the Surface Lamination on Plywood. Journal of the Korean Wood Science and Technology 47(2): 579-586.

Lubis, M.A.R., Jeong, B., Park, B.D., Lee, S.M., Kang, E.C. 2019b. Effect of Synthesis Method and Melamine Content of Melamine-Urea-Formaldehyde Resins on Bond-Line Features in Plywood. Journal of the Korean Wood Science and Technology 47(5): 579-586.

Malkin, A.Y., Kulichikhin, S.G. 1991. Rheokinetics of curing. In: Polymer Compositions Stabilizers/Curing. 
Springer, Berlin, Germany pp. 217-257.

Mattheij, J., Evers, L., Litvinov, V. 2005. The Phenomena of Instability of MUF Resins: Improve your Amino Resin Performance: $9^{\text {th }}$ European Panel Products Symposium. October 5-7. pp. 187-199.

Mijatovic, J., Binder, W.H., Kubel, F., Kantner, W. 2002. Studies on the stability of MF resin solutions: investigations on network formation. In: Macromolecular Symposia, WILEY-VCH Verlag GmbH, Weinheim, Germany 181(1): 373-382.

No, B.Y., Kim, M.G. 2004. Syntheses and properties of low-level melamine-modified urea-melamineformaldehyde resins. Journal of Applied Polymer Science 93(6): 2559-2569.

Nuryawan, A., Park, B.D., Singh, A.P. 2014. Penetration of urea-formaldehyde resins with different formaldehyde/ urea mole ratios into softwood tissues. Wood Science and Technology 48(5): 889-902.

Paiva, N.T., Pereira, J., Ferra, J.M., Cruz, P., Carvalho, L., Magalhães, F.D. 2012. Study of influence of synthesis conditions on properties of melamine- urea formaldehyde resins. International Wood Products Journal 3(1): 51-57.

Paiva, N.T., Pereira, J., Ferra, J.M., Cruz, P., Carvalho, L., Magalha, F.D. 2013. Study of influence of synthesis conditions on properties of melamineurea formaldehyde resins. International Wood Products Journal 3: 51-57.

Pendlebury, E., Lei, H., Antoine, M.L., Pizzi, A. 2010. Melamine-Formaldehyde Resins without Urea for Wood Panels. Journal of Adhesion Science and Technology 24(8-10): 1415-1422

Pizzi, A., Mittal, K. 1994. Handbook of Adhesive Technology. Marcel Dekker, New York, USA.

Siimer, K., Kaljuvee, T., Christjansonoch, P., Pehk, T. 2005. Changes in Curing Behavior of Aminoresins During Storage. Journal of Thermal Analysis and Calorimetry 80: 123-130.

Zanetti, M., Pizzi, A. 2003. Colloidal aggregation of MUF polycondensation resins: formulation influence and storage stability. Journal of Applied Polymer Science 91(4): 2690-2699. 